\title{
Techno-economic impact of collective self-consumption on different energy-related investments for a condominium
}

\author{
Matteo Zatti ${ }^{*}$, Federico Guermandi ${ }^{1,2}$, and Filippo Bovera ${ }^{2}$ \\ ${ }^{1}$ LEAP - Laboratorio Energia Ambiente Piacenza, Via Nino Bixio 27/c, 29121, Piacenza, Italy \\ ${ }^{2}$ Politecnico di Milano, Department of Energy, Via Lambruschini 4a - 20156 Milano
}

\begin{abstract}
Energy Communities (ECs) are gaining a key role in supporting the transition towards a low carbon economy in EU, since they combine the promotion of efficient energy practices with an expected positive social impact. Legislators are resorting to the concept of collective self-consumption as a tool to favor the electrification of energy needs and the diffusion of renewable energy sources. This work presents the first results in this field of the ENERGYNIUS project, co-funded by Regione Emilia-Romagna, focusing on the economic feasibility of investment decisions that would increase energy efficiency and renewables' penetration in the household sector. To this purpose, a mathematical model has been developed, featuring an hourly time step definition of the internal and external energy exchanges and an accurate modelling of the electricity billing. It has been applied to an Italian condominium case study where the energy requirements of the inhabitants - in terms of electricity, heating, cooling and private transportation - have been considered. Thanks to the model, it is possible to compare increasing levels of electrification (e.g., photovoltaic panels, heat pumps, electric vehicles and batteries) and assess the benefits of collective selfconsumption on the condominium cash flows and environment (fossil $\mathrm{CO}_{2}$ emissions).
\end{abstract}

\section{Introduction}

In order to guarantee a sustainable development, EU is promoting a transition towards a low carbon economy. From a technical point of view, the transition entails the maximization of (i) the energy efficiency in all the sectors, or at least in those featuring the largest energy consumption (such as transportation, households and industry) and (ii) the exploitation of renewable energy sources (RES). Electricity is the energy carrier that, at the moment, can best suite both objectives; indeed, it can be extensively produced from RES and also exploited in different energy sectors, above all heating, cooling and transportation (sector coupling), if the proper energy conversion and storage systems are used (see the concept of Smart Energy Systems [1]).

Furthermore, to facilitate the spread of RES, great attention has recently been given to new players in the energy systems: the prosumers (i.e., the crasis of producers and consumers). They are consumers who invest in the installation of energy conversion and/or storage systems (e.g., PV and batteries), and selfconsume the electricity they produce. In order to enhance their positive impact on the environment and on the electricity distribution/transmission infrastructures, $\mathrm{EU}$ has introduced a further new figure: Energy
Communities. They represent a framework for the aggregation of producers, consumers and prosumers under a legally recognized association, wherein members act collectively. They are expected to enable further energy savings and a better management of the self-produced energy, by maximizing the possible synergies among the members of the community. The Clean Energy Package (CEP) - a set of four Regulations and four Directives that intend to shape the European energy polices in the next future in response to the Paris Agreement - marks the first time that the concept of collective self-consumption of renewable energy is formally recognized within EU legislation. The main idea is to give the possibility to a plurality of users to share the production of their renewable energy assets, possibly by using the distribution network.

In particular, the share of energy and the collective management of the energy conversion and storage systems within a group of users is treated in two directives: the recast of Renewable Energy Directive (Directive 2018/2001/EC, often referred as RED II [2]) and the Electricity Market Directive (Directive 2019/944/EC, often referred as EMD II [3]). The first provides the definitions of Renewable Energy Communities (REC) and jointly acting renewable selfconsumers (JARSC), whereas the second of Citizen

\footnotetext{
*Corresponding author: matteo.zatti@polimi.it
} 
Energy Communities (CEC). Such definitions have various similarities, as, in short, they all involve the possibility, for the members, to produce, store, share and sell energy as a community; however, they have some critical differences, which make them suitable for different contexts, as already discussed in [4]. From here on out, we will use the term Energy Community to refer to the common features of the aforementioned definitions.

\section{Energy Communities and the current system}

Besides the reduction of fossil $\mathrm{CO}_{2}$ emissions and the dependency on import of fossil fuels, there are a number of further expected benefits coming from the spreading of jointly acting renewable self-consumers and RECs (as discussed in [5,6]), among which:

- the close-by collective self-consumption of the distributed generation will decrease the electricity injected up-stream into the grid and, consequently, the transmission losses and the need for infrastructural investments;

- should the proper ICT infrastructure be developed, and batteries became a peculiar asset of ECs, they may provide ancillary services to the grid with demand/response type actions;

- self-consumption per se should reduce the costs for energy supplying for final users.

However, there are several issues that have not been directly addressed in the aforementioned EU guiding documents, which Member States will have to sort out in order to avoid technical and economic drawbacks. In the following, we will discuss, among the open questions, those that we find worth discussing in the scope of this study.

First, being preeminently based on intermittent RES, the spreading of Energy Communities will bring about the challenges that characterize this kind of energy source. In particular, the stochasticity associated to PV systems production will combine with the uncertainty of self-consumption profiles, this way the EC injection/withdraw profiles of electricity into/from the grid will make it harder for the TSO and the DSO to guarantee its stability, with a possible need of further infrastructural investments [6,7].

Second, having a dispatching priority, the RES electricity produced by EC will cause trouble to traditional producers to maintain their position into the market. Both the aforementioned issues may have negative economic repercussions on the final customers, as they might see their energy bills increase to sustain the over-costs [8].

Third, if the energy sharing within the community is to be performed physically, i.e. there must be a closed network that connects the users, the reduction of injection into the grid will represent, on one hand, a benefit in terms of loss and overload reduction [6], on the other, it will have a negative fallout on the suppliers, who will see a shrinkage of their sales. In any case, either physical or virtual, they might incur in higher costs for balancing [8].

Fourth, it is not clear how the decision-making power, the investment quota and the redistribution of the payment (that Member States will decide to give to ECs for the RES injection and/or the collectively selfconsumed electricity) will be defined among members of the communities [9].

Fifth, the community will have to interact with a number of private and public subjects operating in the electricity markets and infrastructures (see Fig. 1) and such interaction will require to be specifically regulated [8].

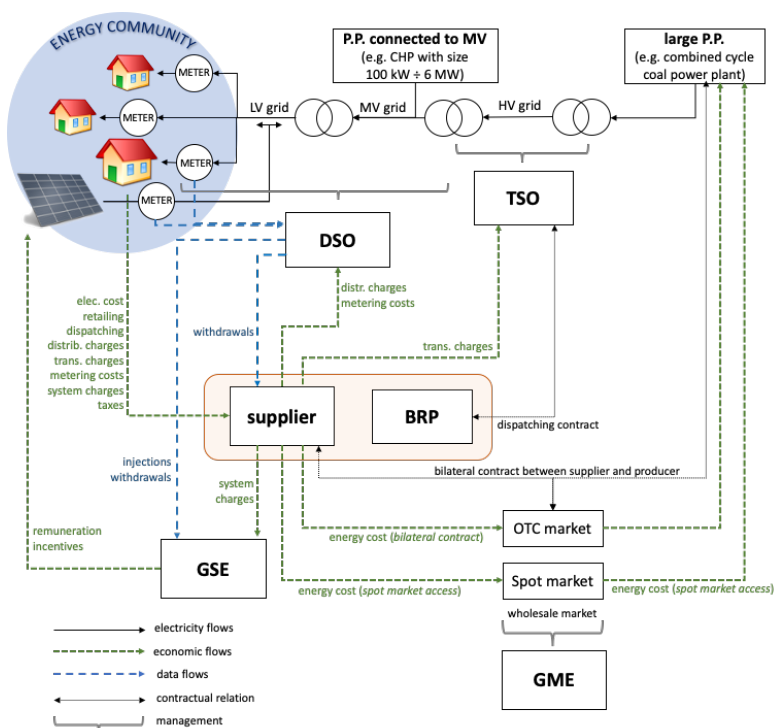

Fig. 1. The Energy Community and the incumbent players of the energy system.

Among the aforementioned two EU Directives, RED II is the one that has got actual implications for the Italian case: it has been absorbed with article $42 \mathrm{bis}$ of the law decree n. 162 of $30^{\text {th }}$ December 2019 coordinated with the law n. 8 of $28^{\text {th }}$ February 2020. Such laws allow the existence and the activity of the very two types of energy communities defined in RED II, with the following specifications:

- jointly acting renewable self-consumers are users who live in the same building (e.g., a condominium) who share, store or sell the output of a collectively own ensemble of RES generation assets, with a maximum total rated power equal to $200 \mathrm{~kW}$;

- renewable energy communities are collections of users with the same prerogatives of the former, yet with a larger perimeter (not just a condominium but a set of buildings located downstream the same $\mathrm{MV} / \mathrm{LV}$ substation) and the rated power, which cannot exceed, individually, the $200 \mathrm{~kW}$.

The consultation document 112/2020/R/eel [5], written by ARERA, the Italian regulation authority for networks energy and environment, defines a regulatory framework to be applied to the jointly acting renewable self-consumers and the renewable energy communities. The main objective of the document is to set the framework for the recognition, from an economic point of view, of the benefits of renewable self-consumption, 
without the necessity for the community to build up new infrastructure (e.g., network connections) or start a company. In order to get such recognition, the members of the community must identify a "representative" for the submission of the request to GSE (the Italian Energy Service Manager). GSE pays for the amount of collectively self-consumed electricity, based on the measurements collected at the points of withdraw and injection (POD) of the consumption and production systems comprised in the community, i.e. the sharing of the self-produced electricity is virtual. Finally, the framework does not affect the current regulation or customer rights. The virtual sharing configuration makes the integration between communities and suppliers unproblematic, as the supply of electricity to the single users occurs in the usual way. On the other hand, the DSO takes on a fundamental role because it is responsible for the real-time measurement of the exchange profiles between the users and the grid.

The remaining of the paper is devoted to the assessment of the techno-economic impact collective self-consumption on different energy-related investments for a condominium, i.e. a group of jointly acting renewable self-consumers.

\section{Assessment methodology}

\subsubsection{Modelling approach}

To assess the economic and environmental impact of both electrification and collective self-consumption for a condominium, we have simulated its yearly operation. It has been assumed that the energy systems of the building are about to be renovated, according to four different scenarios of investments: each scenario features a different employment of electricity-based solutions to satisfy the energy demands and the private transportation requirements of the inhabitants. For each scenario, two configurations have been compared:

- a "business as usual" configuration, where the condominium acts as a group of single users who interacts with the public grid independently (named "single" case);

- an energy community configuration, where there's the possibility to share electricity production between all residents (as a group of jointly acting renewable self-consumers, named "EC" case).

Furthermore, for the energy community configuration, both the virtual, as foreseen in the Italian case (named "EC-VS"), and the physical sharing (named "EC-PS") are considered. The combination of the four scenarios and the three configuration generates a total of twelve cases. The operating costs and the fossil $\mathrm{CO}_{2}$ emissions, associated to the fulfilment of the energy and private transportation needs of the inhabitants in the twelve cases, have been computed thanks to a Mixed Integer Linear Programming problem.

The simulation of the condominium operation throughout the year is carried out considering five typical days, each one to represent a typical period/condition: extreme winter, winter, mid-season, summer and extreme summer. The total annual results are computed by weighting the typical days values, according to the fraction of the year that they represent. Further details are given in the following sections.

\subsubsection{Problem statement}

The optimization problem ca be stated as follows: given: (i) the design of the condominium (in terms of installed technologies, their characteristic performance and parameters), (ii) the energy demands of the residents, (iii) the prices and structure of the bills of natural gas and electricity, (iv) the production profiles of the intermittent RES and (v) the single/EC configuration, determine the optimal management of the energy conversion and storage units and exchange with the grid so as to minimize the operating costs of the condominium as a whole.

The objective function can be formulated as follows:

$$
\min \sum_{d} N_{d}\left[\sum_{h} \sum_{i}\left(\xi_{i, d, h}^{E B}+\xi_{i, d, h}^{N G}-\varphi_{i, d, h}^{E R}\right)\right]
$$

Where: $d \in D, h \in\{1 \ldots 24\}$ and $i \in P O D s$ are the sets of typical days, hours of the day and points of delivery, respectively; $N_{d}$ is the number of days represented by typical day $d ; \xi_{i, d, h}^{E B}$ and $\varphi_{i, d, h}^{E R}$ are the electricity bill and the electricity remuneration, respectively, computed accordingly to the considered configuration; $\xi_{i, d, h}^{N G}$ is the natural gas bill, which is computed whose computation method is independent of the configuration. The electricity bill features an energy, a power and a fixed quota, plus taxes paid on total consumption, hence $\xi_{i, d, h}^{E B}$ is calculated as the hourly contribution to the total amount paid in the bill. Moreover, for the EC-PS configuration, also the fees for the operation of the internal distribution network are taken into account. The electricity remuneration corresponds to:

- the payment of the hourly zonal price for the electricity injected into the grid for the singles and the EC-PS configurations (together with a reduction of the bill due to the physically self-consumed energy);

- the payment of a $80 € / M W h$ feed-in-tariff (FIT) for all the electricity injected into the grid plus a bonus for the shared electricity, whose values are defined according to the incentive levels set by the Italian Government in DM 04/07/2019 [10] and by ARERA [5], respectively.

Similarly, $\xi_{i, d, h}^{N G}$ comprises the fixed and the energy quota, plus taxes for the natural gas bill.

The constraints of the model govern energy balances, storage management, exchange profiles with the grid, bill calculation and electric vehicle charging.

\subsubsection{Case study and scenarios}

The study considers a condominium located in EmiliaRomagna, Northern Italy. The condominium is occupied by three categories of users: couple of elderly people, 
couple of young workers and family with two children each. There are three apartments for each category in the condominium (total: nine apartments). The electricity, heating (space and domestic hot water) and cooling demands have been considered, plus the private transportation needs of the inhabitants. To define the profiles of the energy demands, reference values for annual consumption and daily profiles have been considered [11-13] and then shaped according to a hypothetical typical behavior for each category of resident. As for the private transportation, different distances and type of vehicles have been considered for each category. In two scenarios, some of the traditional vehicles are substituted with electric ones. For them, it has been assumed that the consumption is $0,17 \mathrm{kWh} / \mathrm{km}$ and $85 \%$ of the charge occurs at home, Main data and assumptions are listed in Table 1.

Table 1. Annual demands of user categories. Vehicles marked with $*$ are replaced by electric vehicles in scenarios $C$ and $D$.

\begin{tabular}{|l|c|c|c|c|}
\hline & Oldies & $\begin{array}{c}\text { Young } \\
\text { couple }\end{array}$ & \multicolumn{2}{|c|}{$\begin{array}{c}\text { Family } \\
\text { with kids }\end{array}$} \\
\hline $\begin{array}{l}\text { Ap. Surface } \\
\text { [m²] }\end{array}$ & 80 & 80 & \multicolumn{2}{|c|}{120} \\
\hline $\begin{array}{l}\text { Electricty } \\
\text { [kWh] }\end{array}$ & 2.700 & 2.400 & \multicolumn{2}{|c|}{3.200} \\
\hline $\begin{array}{l}\text { Space heating } \\
\text { [kWh] }\end{array}$ & 4.784 & 4.784 & \multicolumn{2}{|c|}{7.176} \\
\hline DHW [kWh] & 1.160 & 1.160 & \multicolumn{2}{|c|}{1.740} \\
\hline Cooling [kWh] & 1.200 & 1.200 & \multicolumn{2}{|c|}{1.800} \\
\hline Vehicle & methane & gasoline* & diesel & lpg* \\
\hline Distance [km] & 5.000 & 11.000 & 17.000 & 8.000 \\
\hline $\begin{array}{l}\text { Daily EV } \\
\text { charge [kWh] }\end{array}$ & - & 4,43 & - & 3,3 \\
\hline $\begin{array}{l}\text { EV charge time } \\
\text { interval [h] }\end{array}$ & & $\begin{array}{c}11 \text { p.m. } \\
7 \text { a.m. }\end{array}$ & & $\begin{array}{l}8 \text { p.m. } \\
8 \text { a.m. }\end{array}$ \\
\hline
\end{tabular}

The features of the four scenarios (from A to D) are reported in Table 2. A reference scenario has been defined in order to express all results as variations with respect to it. Each scenario considers a series of energy renovation investments. Units are divided by POD of installation: either on user POD or on condominium POD. The condominium units serve a centralized distribution system. As previously mentioned, the conceived scenarios feature a progressive electrification. Scenario A can be regarded as first step, assuming that a single user installs a PV system. Scenario B is characterized by the partial electrification of the heating system: it is endowed with a hybrid system (air/water heat pump + integration boiler), supported by a thermal storage. The model can decide whether to use the HP or the boiler, for example when the HP performances are penalized by low ambient air temperature or when HP is not sufficient to meet the total heating demand, and how to exploit the storage. In scenario $\mathrm{C}$, the electricity demand for charging the EVs is added, which represent a partial electrification of the private transportation. The charging station is associated to the condominium POD. Finally, scenario D has a 10-
$\mathrm{kWh}$ electric storage system installed, giving a further degree of freedom to the condominium.

Table 2. Details of the scenarios used in the study. Sizes are expressed in $\mathrm{KW}$ of output of the unit: $\mathrm{kWc}$ for the air conditioning (AC), $\mathrm{kWt}$ for the boiler (BOIL.) and the heat pump (HP), except for the PV (m2) and the battery (kWh).

\begin{tabular}{|c|c|c|c|c|c|c|}
\hline \multirow{4}{*}{$\begin{array}{c}\text { Single } \\
\text { user } \\
\text { domain }\end{array}$} & & \multicolumn{5}{|c|}{ Scenarios } \\
\hline & & Ref. & $\mathbf{A}$ & B & $\mathbf{C}$ & D \\
\hline & PV & n.a. & \multicolumn{4}{|c|}{$20 \mathrm{~m}^{2}$ (for one user only) } \\
\hline & AC & \multicolumn{5}{|c|}{$\begin{array}{l}5,57 \mathrm{kWc} \text { (young couple, oldies); } \\
8,02 \mathrm{kWc} \text { (family with kids) }\end{array}$} \\
\hline \multirow{5}{*}{ 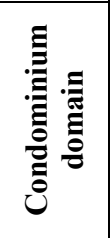 } & PV & \multicolumn{2}{|c|}{ n.a. } & $40 \mathrm{~m}^{2}$ & \multicolumn{2}{|c|}{$60 \mathrm{~m}^{2}$} \\
\hline & BOIL. & \multicolumn{2}{|c|}{$110 \mathrm{kWt}$} & \multicolumn{3}{|c|}{$70 \mathrm{kWt}$} \\
\hline & HP & \multicolumn{2}{|c|}{ n.a. } & \multicolumn{3}{|c|}{$42 \mathrm{kWt}$} \\
\hline & TANK & \multicolumn{2}{|c|}{ n.a. } & \multicolumn{3}{|c|}{1000 litres } \\
\hline & BATT. & \multicolumn{4}{|c|}{ n.a. } & $\begin{array}{c}10 \\
\mathrm{kWh}\end{array}$ \\
\hline \multirow{2}{*}{ 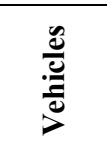 } & ICE & \multicolumn{3}{|c|}{$\begin{array}{l}\text { Diesel (x3), gasoline } \\
(\mathrm{x} 3), \text { methane }(\mathrm{x} 3) \text {, } \\
\operatorname{lpg}(\mathrm{x} 3)\end{array}$} & \multicolumn{2}{|c|}{$\begin{array}{l}\text { Diesel (x3), } \\
\text { methane (x3) }\end{array}$} \\
\hline & EV & \multicolumn{3}{|c|}{ n.a. } & \multicolumn{2}{|c|}{$2(\mathrm{x} 3)$} \\
\hline
\end{tabular}

\section{Results}

Results concerning gas consumption and electricity balances (inside the community and with the grid), associated $\mathrm{CO}_{2}$ emissions and operating expenses are reported in Table 3.

In both the communitarian configurations, selfconsumption is recognized as a convenient practice and, therefore, maximized by the model. The sale of electricity, indeed, occurs only when the condominium cannot further accommodate the production (see physical sharing configuration in Fig. 2). The thermal storage is discharged in the morning to match the heating demand, helped by the HP; it is re-charged by the HP during the afternoon, when the PV production is in excess with respect to the electricity demand. Furthermore, the model takes advantage of the high sale price at 10 a.m. in the morning and slightly shift the thermal storage charge to the later hours, when selling electricity would be less economically convenient.

Back to Table 3, as expected, the addition of a storage unit (scenario D) enhances the capacity of the condominium to host the self-production (same PV production of scenario $\mathrm{C}$, yet the self-consumption is 2,13 MWh larger (i.e., +14\%)).

The reduction in natural gas consumption (see the shift from scenario A to B) and the partial electrification of transportation (scenario B to C) leads to remarkable reduction of operating expenditures for the condominium, i.e. $-86 \%$ and $-51 \%$ of gas and fuel yearly expenditures, respectively. Economics savings due to collective electricity self-consumption are, instead, less relevant: they lay in (i) the reduction in electricity bill due to the physical sharing (up to $-0,79 \mathrm{k} € /$ year with respect to the single users configuration in scenario $\mathrm{C}$ ), and in the increase in remuneration due to the virtual sharing (up to $+0,20 \mathrm{k} € /$ year with respect to the single users configurations, in scenario C). 
Table 3. Results of the annual simulation. Values in Scenarios A, B, C and D are expressed as difference with respect to the Reference Scenario.

\begin{tabular}{|c|c|c|c|c|c|c|c|c|c|c|c|c|c|c|c|}
\hline & & & & & & & & & & & & & & \\
\hline & & & \multicolumn{13}{|c|}{ Scenarios } \\
\hline & & \multirow{2}{*}{ u.m. } & \multicolumn{4}{|c|}{$\mathbf{A}$} & \multicolumn{3}{|c|}{ B } & \multicolumn{3}{|c|}{$\mathbf{C}$} & \multicolumn{3}{|c|}{ D } \\
\hline & & & Ref. & \multicolumn{3}{|c|}{\begin{tabular}{|l|l|l|} 
Single & EC-PSEC-VS \\
\end{tabular}} & Single & \multicolumn{2}{|c|}{ EC-PSEC-VS } & Single & \multicolumn{2}{|c|}{ EC-PSEC-VS } & \multicolumn{3}{|c|}{\begin{tabular}{|l|l|l|} 
Single EC-PS & EC-VS \\
\end{tabular}} \\
\hline \multicolumn{2}{|c|}{\begin{tabular}{|l|l|} 
Gas consumption \\
\end{tabular}} & $\mathrm{kSm}^{3}$ & 10,63 & \multicolumn{3}{|c|}{0} & \multicolumn{3}{|c|}{$-10,15$} & \multicolumn{3}{|c|}{$-10,15$} & \multicolumn{3}{|c|}{$-10,15$} \\
\hline \multirow{7}{*}{ } & consumption & MWh & 29,29 & \multirow{2}{*}{\multicolumn{3}{|c|}{$\frac{0}{+3,85}$}} & \multicolumn{3}{|c|}{$+15,87$} & \multicolumn{3}{|c|}{$+24,12$} & \multicolumn{3}{|c|}{$+24,11$} \\
\hline & production & MWh & 0 & & & & \multicolumn{3}{|c|}{$+11,54$} & \multicolumn{3}{|c|}{$+15,39$} & \multicolumn{3}{|c|}{$+15,39$} \\
\hline & import & MWh & 29,29 & \multicolumn{3}{|c|}{$\frac{+3,85}{-3,85}$} & $+10,25$ & \multicolumn{2}{|c|}{$+5,30$} & $+17,14$ & \multicolumn{2}{|c|}{$+12,09$} & $+14,68$ & \multicolumn{2}{|c|}{$+9,94$} \\
\hline & export & MWh & 0 & $+2,34$ & \multicolumn{2}{|c|}{$\frac{0}{-5,0 J}$} & $+5,91$ & +0 & 97 & $+8,41$ & +3 & 36 & $+5,97$ & +1 & 22 \\
\hline & self-consumption & MWh & 0 & $+1,51$ & & 85 & $+5,63$ & +1 & 0,57 & $+6,98$ & +12 & 2,03 & $+9,42$ & +12 & 4,16 \\
\hline & physical self cons. ratio & $\%$ & 0 & $39 \%$ & $100 \%$ & $39 \%$ & $49 \%$ & $92 \%$ & $49 \%$ & $45 \%$ & $78 \%$ & $45 \%$ & $61 \%$ & $92 \%$ & $61 \%$ \\
\hline & virtual self cons. ratio & $\%$ & 0 & - & - & $61 \%$ & - & - & $43 \%$ & - & - & $33 \%$ & - & - & $31 \%$ \\
\hline & electricity & ton & 9,67 & $-1,23$ & & 27 & $+1,54$ & +1 & 45 & $+3,52$ & +3 & 42 & $+3,47$ & &, 38 \\
\hline 2 & gas & ton & 20,88 & & 0 & & & $-19,94$ & & & $-19,94$ & & & $-19,94$ & \\
\hline U & fuels & ton & 17,98 & & 0 & & & 0 & & & $-8,47$ & & & $-8,47$ & \\
\hline & TOT & ton & 48,53 & $-1,23$ & & 27 & $-18,40$ & -18 & 8,49 & $-24,89$ & -24 & 4,98 & $-24,94$ & & 5,03 \\
\hline & electricity exchange: & $\mathbf{k €}$ & 6,19 & $-0,38$ & $-0,59$ & $-0,44$ & $+2,56$ & $+2,10$ & $+2,40$ & $+3,48$ & $+3,01$ & $+3,28$ & $+3,24$ & $+2,78$ & $+3,09$ \\
\hline.$\ddot{\theta}$ & bill & $\mathbf{k} €$ & 6,19 & $-0,23$ & $-0,59$ & $-0,23$ & $+2,93$ & $+2,16$ & $+2,93$ & $+4,01$ & $+3,22$ & $+4,01$ & $+3,62$ & $+2,86$ & $+3,62$ \\
\hline$\ddot{\Xi}$ & remuneration & $\mathbf{k} €$ & 0 & $+0,14$ & 0 & $+0,21$ & $+0,37$ & $+0,06$ & $+0,52$ & $+0,52$ & $+0,21$ & $+0,72$ & $+0,38$ & $+0,08$ & $+0,52$ \\
\hline 0 & gas & $\mathbf{k €}$ & 5,88 & & 0 & & & $-5,09$ & & & $-5,09$ & & & $-5,09$ & \\
\hline 氖 & vehicle fuels & $\mathbf{k} €$ & 9,46 & & 0 & & & 0 & & & $-4,66$ & & & $-4,66$ & \\
\hline & TOT & $\mathrm{k} €$ & 21,53 & $-0,38$ & $-0,59$ & $-0,44$ & $-2,53$ & $-2,98$ & $-2,68$ & $-6,27$ & $-6,74$ & $-6,46$ & $-6,51$ & $-6,96$ & $-6,65$ \\
\hline
\end{tabular}

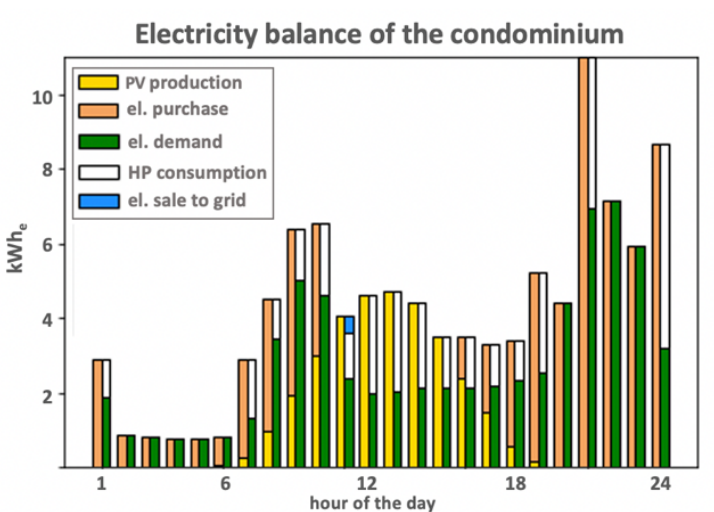

Thermal balance of the condominium

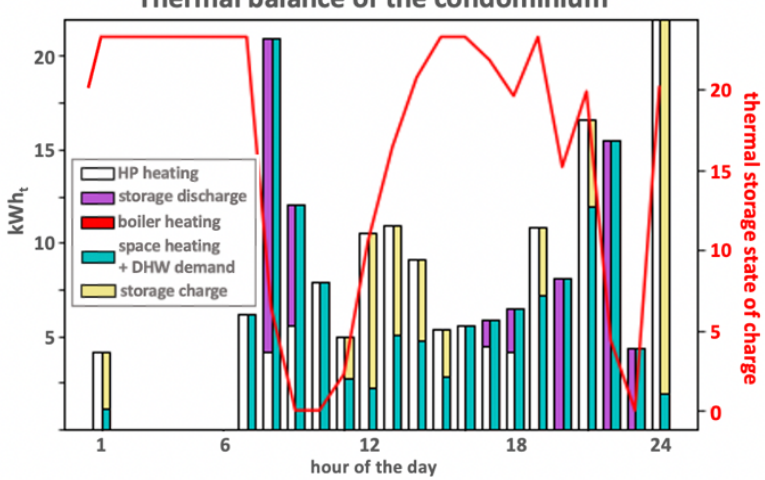

Fig. 2. Hourly management strategy of the condominium assuming the EC-PS configuration in the mid-season typical day. For each our, the left column represents the production/withdrawal from the grid, the right column represents the consumption/injection into the grid.

Overall, economic savings for the members of the community are higher in the physical sharing configuration: in fact, the average price paid in the bill is $211 € / \mathrm{MWh}$, higher than the FIT tariff employed in this study. In light of the issues discussed in section 2, however, the repercussions that this configuration would have on incumbent players makes it implementation quite challenging.

$\mathrm{CO}_{2}$ emissions shows a similar behavior: despite the higher values due to the extra electricity consumption, electrification of heating and transports leads to significant overall reductions (up to $-25 \mathrm{tCO}_{2}$ (i.e., $52 \%$ ) in scenario $\mathrm{D}$, with respect to the reference scenario). The impact of self-consumption, on the other hand, is essentially due to the reduction of transmission losses and the corresponding emissions savings, therefore is rather limited compared to electrification.

As for the investments, Fig. 3 shows that the savings in the operating expenditures increases with the investment in electricity-based equipment, however the actual annual net savings depend on the selfconsumption configuration. The net savings are the results not only of the decrease of expenses for the energy carriers (i.e., withdrawn electricity, natural gas and traditional fuels), but also of the fiscal advantages for heat pumps and PV panels installation foreseen by the current Italian legislation (advantages due to high efficiency air conditioning units and boilers have also been considered) and in the reduction of O\&M costs, in particular those associated to the substitution of ICEbased vehicles with EVs (scenario D vs. C).

As shown in Fig. 4 and Fig. 5, in scenario A net annual savings are too low for the investment to be recovered within 10 years; in this scenario, collective selfconsumption significantly reduces the payback time, especially in cases of physical sharing (- 6 years with respect to the single users configuration). The payback time of scenarios B, C and D is shorter (in the range 5,9 to 7,8 years), making such investments interesting for residents. In particular, despite the high extrainvestment, scenario $\mathrm{C}$ features a high net present values after a decade, in front of a slight increase in payback time with respect to scenario $\mathrm{B}$. In scenario $\mathrm{D}$, despite 
the highest annual savings, the return of the investment is hindered by the considerably high capital cost of the battery.

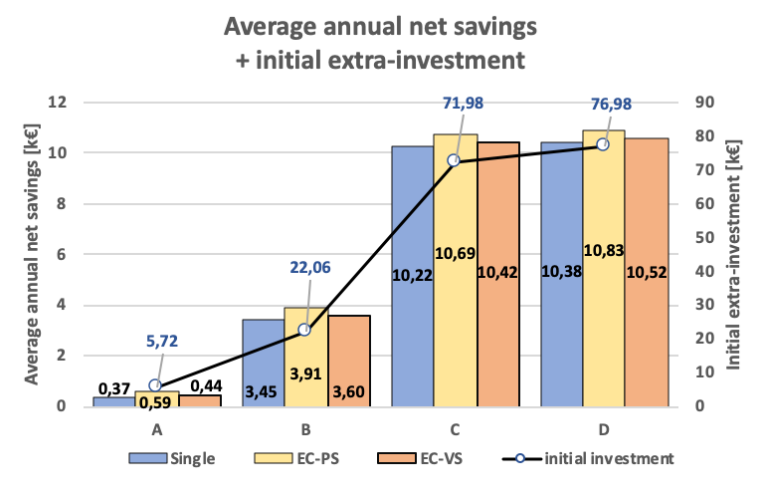

Fig. 3. Average annual net savings and initial extra-investment in the four scenarios with respect to Reference Scenario.

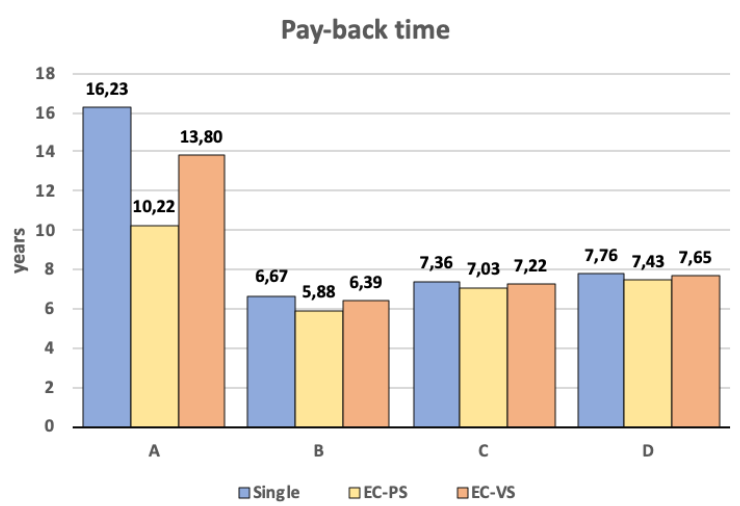

Fig. 4. Pay-back time of the investment.

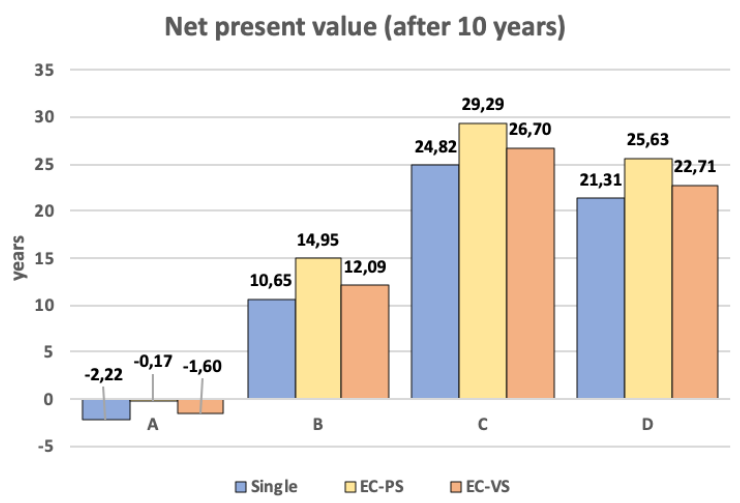

Fig. 5. Net Present Value in 10 years.

\section{Conclusions}

In the framework of the Energy Communities, a methodology to simulate the operation of a group of users that can collectively self-consume renewable energy has been developed. The model has been used to assess the impact of electrification and different collective self-consumption configurations on the cash flows and the $\mathrm{CO}_{2}$ emissions of a condominium. Results show that in all scenarios collective self-consumption rises the annual savings in front of no extra investment with respect to the single users configuration, however its contribution to the business model remains less relevant than the one of electrification. Physical sharing allows for the largest economic advantages for the community with respect the single users configurations (up to $+40 \%$ NPV in 10 years, scenario B), but virtual sharing configuration features a very limited effect on incumbent players and the current regulatory framework. Results show good economic performances, especially considering scenario B which is the most feasible in the short-term from an implementation point of view; however, scenario $C$ and $D$ are more interesting in the long-term perspective, also considering that both EVs and batteries could have a role in the provision of dispatching services to the public grid in the future. Moreover, their higher NPV could be attractive for external investors selling transport and energy production as third-party services to consumers within an EC frame.

Future works will focus on comparing ECs with other prosumers-related framework currently in place in Italy, and on developing a tool to find the optimal incentivization level for ECs regulation.

This work was supported by the "Energynius - Energy networks integration for urban systems" project (CUP E31F18001040007) co-funded by Regione Emilia-Romagna through the European Regional Development Fund 20142020 .

\section{References}

1. H. Lund, P.A. Østergaard, D. Connolly, B.V. Mathiesen, Energy, 137 (2017).

2. European Parliament and Council, Directive (EU) 2018/2001 (2018).

3. European Parliament and Council, Directive (EU) 2019/944 (2019).

4. D. Frieden, A. Tuerk, J. Roberts, S. d'Herbemont, A Gubina. Collective self-consumption and energy communities: Overview of emerging regulatory approaches in Europe (2019).

5. ARERA, DCO 112/2020/R/eel (2020).

6. T. Couture, G. Barbose, D. Jacobs, G. Parkinson, E. Chessin, A. Belden, H. Wilson, H. Barrett, W. Rickerson, Residential Prosumers: Drivers and Policy Options (2014).

7. ARERA, Memoria 12 marzo 2019 (2019).

8. CEER, Regulatory Aspects of Self-Consumption and Energy Communities (2019).

9. S. O'Brien, C. Monteiro, M. Gancheva, N. Crook, Models of Local Energy Ownership and the Role of Local Energy Communities in Energy Transition in Europe (2018).

10. MiSE, $D M$ 04/07/2019 (2019).

11. M. Gallanti, W. Gratteri, S. Maggiore, A. Marino, Analisi ed evoluzione negli anni delle curve di carico dei clienti domestici (2012).

12. The Episcope project, Episcope (2016).

13. D.Fischer, K. Byskov Lindberg, H. Madani, C. Wittwer, Impact of $P V$ and Variable Prices on Optimal System Sizing for Heat Pumps and Thermal Storage (2016). 